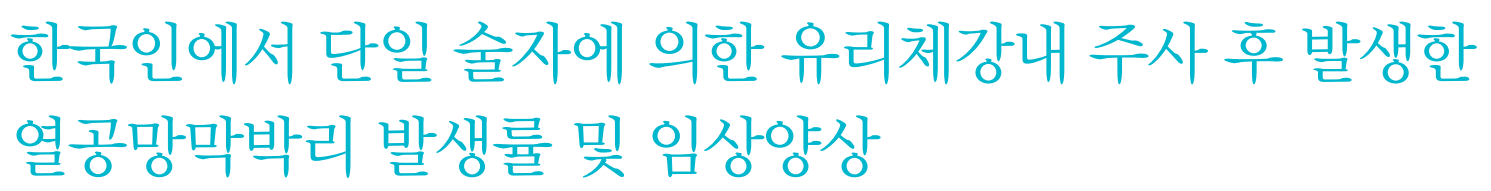

\title{
Incidence and Clinical Features of Rhegmatogenous Retinal Detachment After 9,484 Intravitreal Injections by a Single Physician
}

\author{
한재용 ${ }^{1}$, 강현구 $^{1}$, 최은영 ${ }^{1}$, 이성철 $^{2}$, 김 민 $^{1}$ \\ Jae Yong Han ${ }^{1}$, Hyun Goo Kang ${ }^{1}$, Eun Young Choi ${ }^{1}$, Sung Chul Lee ${ }^{2}$, Min Kim ${ }^{1}$ \\ 1연세대학교 의과대학 안과학교실 시과학연구소, ${ }^{2}$ 건양대학교 의과대학 안과학교실 \\ ${ }^{1}$ Institute of Vision Research, Department of Ophthalmology, Yonsei University College of Medicine, Seoul, Korea \\ ${ }^{2}$ Department of Ophthalmology, Konyang University College of Medicine, Daejeon, Korea
}

Purpose: To report the incidence of rhegmatogenous retinal detachment (RRD) following intravitreal injections and describe its clinical features.

Methods: The medical records of patients who received intravitreal injections from a single retinal specialist between February 2012 and January 2019 at a tertiary referral-based hospital and who had at least three months of follow-up data were analyzed retrospectively.

Results: In total, 9,484 intravitreal injections were performed by a single physician in 1,739 eyes of 1,480 patients during the study period. The mean patient age was 59.7 years at the time of the first injection. Patients received an average of 5.3 injections per eye during a mean follow-up period of 26.3 months. RRD occurred as a complication in only one case for an overall incidence rate of $0.01 \%$ per injection and 0.06\% per eye. In that specific case, RRD occurred two weeks after an intravitreal injection, and the retina was successfully reattached without recurrence after prompt vitrectomy.

Conclusions: The observed incidence rate of RRD after intravitreal injection was extremely low, similar to that reported in previous studies.

Keywords: Incidence; Intravitreal injection; Rhegmatogenous retinal detachment

\section{Introduction}

Intravitreal injection is a treatment modality adopted widely in many diseases, including exudative age-related macular degeneration (AMD), retinal vein occlusion with macular edema, diabetic macular edema, proliferative diabetic reti- nopathy (PDR) with vitreous hemorrhage, and choroidal neovascularization secondary to various chorioretinal diseases including central serous chorioretinopathy. Intravitreal injections are reported to be administered 5.6 to 13 times per year on average in patients with AMD [1] and 5.8 times per year in those with diabetic retinopathy [2]. Moreover, the number of patients receiving intravitreal injections is increasing $[3,4]$,

\section{Address reprint requests to Min Kim, MD}

Institute of Vision Research, Department of Ophthalmology, Gangnam Severance Hospital, Yonsei University

College of Medicine, \#211 Eonju-ro, Gangnam-gu, Seoul 06273, Korea

Tel: 82-2-2019-3440, Fax: 82-2-3463-1049

E-mail: Minkim76@gmail.com
Received: 2020. 2. 17.

Revised: 2020. 4. 24.

Accepted: 2020. 5. 3. 
with most needing to receive continuous treatment to maintain the therapeutic efficacy. Many studies have sought to discern the best way to minimize the various potential side effects of intravitreal injections [5-7], but severe complications continue to appear, including endophthalmitis $(0.3 \%)$, cataract $(0.2-3.6 \%)$, and rhegmatogenous retinal detachment (RRD) $(0.9 \%)$ [8-11]. Of critical importance in the injection process is to perform the injection at approximately 3.5 to $4 \mathrm{~mm}$ from the limbus, given that penetration at more than $4.5 \mathrm{~mm}$ from the limbus may damage the anterior base of the vitreous and ora serrata. Such trauma can cause severe damage to all layers of the retina, including retinal tears or holes, that can progress to vision-threatening conditions such as vitreous hemorrhage, RRD, and choroidal detachment [12]. Although there have been reports on the incidence of RRD after intravitreal injection, to our knowledge, there have been no studies performed only in Korean patients. Furthermore, most studies that have included large numbers of participants have entailed the pooling of data from multiple centers with multiple physicians or are limited by a relatively small sample size of patients treated by a single physician [6]. In contrast, this study sought to report the incidence of RRD after intravitreal injections by a single physician in comparison with that reported previously and to describe the clinical features and outcomes in a large number of patients who received intravitreal injections from a single physician.

\section{Materials and Methods}

The study was approved by the Institutional Review Board of Yonsei University Gangnam Severance Hospital (IRB No. 3-2019-0283) and adhered to the tenets of the Declaration of Helsinki and the Good Clinical Practice guidelines. We retrospectively reviewed the medical records of patients who received intravitreal injections administered by a single retinal specialist (M. K.) between February 2012 and January 2019. Demographic data at baseline, including patient age and sex, and clinical data such as diagnoses, the number of intravitreal injections received, and the agent injected, were collected.

All patients provided written informed consent, which was documented electronically before each injection. The injection was administered in an operating room or a treatment room in the outpatient clinic. A topical dilating agent
(0.5\% tropicamide $/ 0.5 \%$ phenylephrine, Tropherine ${ }^{\circledR} ;$ Hanmi Pharm Co. Ltd., Seoul, Korea) was administered 30 minutes before injection. Additionally, topical $0.5 \%$ proparacaine hydrochloride (Alcaine ${ }^{\circledR}$; Alcon, Fort Worth, TX, USA) was instilled in the eye before each injection, followed by application of a povidone-iodine swab to the eyelid, eyelashes, and lid margin. A sterile speculum was inserted, and 5\% povidone-iodine solution was introduced over the ocular surface to sterilize the conjunctival sac. The intravitreal injection was performed at 3.5 to $4.0 \mathrm{~mm}$ from the limbus, mainly in the superotemporal or inferotemporal quadrant. A 30-gauge needle was used for all injections, except those involving Ozurdex ${ }^{\circledR}$ (Allergan Inc., Dublin, Ireland), for which an enclosed 22-gauge needle was used. All patients received topical $0.3 \%$ gatifloxacin (Gatiflo ${ }^{\circledR}$; Handok, Seoul, Korea) for one week after each injection $[6,7,13]$.

Patients were followed up at one month after each injection. All patients underwent a fundus examination including ultra-widefield scanning laser ophthalmoscopy (Optomap; Optos, Marlborough, MA, USA) and dilated binocular indirect ophthalmoscopy at each visit. Patients were provided with verbal and written instructions to visit the clinic earlier or to contact a local ophthalmologist if they developed sudden floaters, flashes, a visual field defect, loss of vision, eye pain, or redness. Patients presenting to our clinic with such symptoms were examined immediately. Patients with less than three months of follow-up data after treatment were excluded.

All fundus images, time of occurrence, features of the condition, and the course of treatment were reviewed if RRD developed after intravitreal injection. All statistical analyses were performed using the Statistical Package for the Social Sciences for Windows (version 23.0; IBM Corp., Armonk, NY, USA).

\section{Results}

A total of 9,484 injections was performed in 1,739 eyes of 1,480 patients. The mean patient age at the time of the first injection was $59.7 \pm 17.6$ (range, 0-94) years, and 842 patients $(56.9 \%)$ were male. The mean follow-up duration was $26.3 \pm 19.3$ (range, 3.0-82.0) months (Table 1). The average number of injections per eye was $5.3 \pm 6.5$ (range, 1-46). The agents injected were as follows: bevacizumab (Avastin ${ }^{\circledR}$; Genentech Inc., San Francisco, CA, USA) in 5,766 (60.8\%); 
aflibercept (Eylea ${ }^{\circledR}$; Bayer, Leverkusen, Germany) in 1,603 (16.9\%); ranibizumab (Lucentis ${ }^{\circledR}$; Genentech Inc.) in 1,385 (14.6\%); dexamethasone intravitreal implant (Ozurdex ${ }^{\circledR}$; Allergan, Inc.) in 654 (6.9\%); and others (including ganciclovir [Cymevene ${ }^{\circledR}$; Hoffmann-La Roche, Welwyn Garden City, UK], steroids, antibiotics, and antifungals) in $76(0.8 \%)$ (Table 1).

The most common condition requiring intravitreal injection was exudative AMD ( $\mathrm{n}=353,23.9 \%)$, which was followed by vitreous hemorrhage associated with diabetic retinopathy $(\mathrm{n}=286 ; 19.3 \%)$, retinal vein occlusion with

Table 1. Baseline characteristics of the study population

\begin{tabular}{lc}
\hline Characteristic & Value \\
\hline Total number of injections performed & 9,484 \\
\hline Total number of subjects/eyes & $1,480 / 1,739$ \\
\hline Age at time of first injection (years) & $59.7 \pm 17.6$ \\
Sex (male) & $842(56.9)$ \\
Injections performed & $9,484(100)$ \\
Bevacizumab & $5,766(60.8)$ \\
Aflibercept & $1,603(16.9)$ \\
Ranibizumab & $1,385(14.6)$ \\
Dexamethasone implant & $654(6.9)$ \\
Other (antibacterial, antiviral, or antifungal) & $76(0.8)$ \\
Follow-up duration (months) & $26.3 \pm 19.3$ \\
\hline
\end{tabular}

Values are presented as mean \pm standard deviation or number (\%).

Table 2. Diagnoses of patients treated with intravitreal injections

\begin{tabular}{lr}
\hline Diagnose & Value \\
\hline Neovascular age-related macular degeneration & $353(23.9)$ \\
$\begin{array}{l}\text { Proliferative diabetic retinopathy with vitreous } \\
\text { hemorrhage }\end{array}$ & $286(19.3)$ \\
Retinal vein occlusion with macular edema & $221(14.9)$ \\
Diabetic macular edema & $169(11.4)$ \\
Central serous chorioretinopathy & $146(9.9)$ \\
Uveitis (including uveitic macular edema) & $89(6.0)$ \\
Retinopathy of prematurity & $33(2.2)$ \\
Cytomegalovirus retinitis & $22(1.5)$ \\
Hypertensive retinopathy & $9(0.6)$ \\
Retinal vasculitis & $6(0.4)$ \\
Other (including endophthalmitis and acute & $146(9.9)$ \\
$\quad$ retinal necrosis) & 1,480 \\
\hline Total & \\
\hline
\end{tabular}

Values are presented as number (\%). macular edema $(\mathrm{n}=221,14.9 \%)$, diabetic macular edema $(\mathrm{n}=169,11.4 \%)$, central serous chorioretinopathy $(\mathrm{n}=146$, $9.9 \%)$, and uveitis ( $\mathrm{n}=89,6.0 \%$ ) (Table 2 ).

The occurrence of RRD was noted as a complication in only one eye from one patient, yielding incidence rates of $0.01 \%$ per injection and $0.06 \%$ per injected eye. This complication occurred in a 36-year-old man with a diagnosis of PDR accompanied by vitreous hemorrhage in his left eye who received three consecutive intravitreal injections of bevacizumab. He was scheduled to return for an outpatient follow-up visit at one month after the final injection but experienced sudden vision loss in the treated eye after only two weeks. Dilated fundus examination revealed a peripheral retinal tear at the superotemporal quadrant with bullous retinal detachment in the temporal half of the retina involving the macula (Fig. 1). The patient underwent prompt vitrectomy with gas tamponade. During subsequent postoperative follow-up, the patient remained stable without complications, such as recurrence of RRD, or need for additional injections or other treatment.
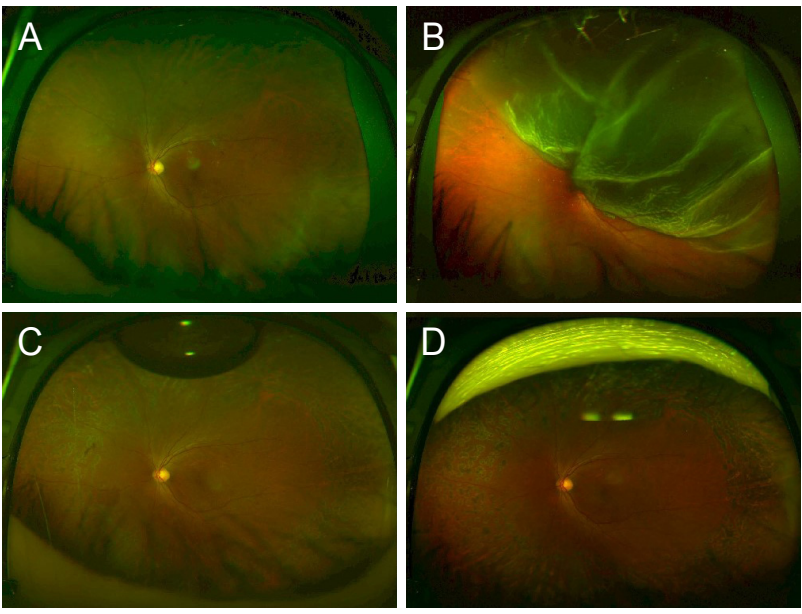

Figure 1. Retinal detachment after intravitreal injection of anti-vascular endothelial growth factor in a 36-year-old man diagnosed with proliferative diabetic retinopathy accompanied by vitreous hemorrhage in his left eye. (A) A wide-field fundus image acquired before intravitreal bevacizumab injection shows residual vitreous hemorrhage without peripheral retinal breaks. (B) Two weeks after intravitreal bevacizumab injection, a bullous retinal detachment was evident. (C) After prompt vitrectomy, a well-attached retina can be seen at one month postoperatively. (D) Follow-up imaging at 18 months after surgery revealed a stable flat retina with peripheral scarring from laser photocoagulation. 


\section{Discussion}

In the present retrospective review of 9,484 intravitreal injections performed by a single retinal specialist, we identified only one case complicated by RRD among 1,739 eyes from 1,480 patients, for an incidence rate of $0.01 \%$ per injection. According to previous studies, the incidence of RRD after intravitreal injection varies from $0 \%$ to $0.9 \%[6,7,9,14-20]$. The incidence in our study, which is based on a relatively large number of cases, was significantly lower than that in previous reports. This discrepancy may reflect differences in study design such as number of physicians involved, perioperative procedures, and the treating physician's proficiency and technique.

Park et al. [21] reported that 10.39 cases of RRD per 100,000 people in South Korea occurred from 2007 to 2011, which is an incidence of $0.01 \%$. This rate is similar to that in our study, suggesting that intravitreal injection does not necessarily increase the risk of RRD compared to its incidence in the general population if appropriate perioperative management protocols and injection techniques are used. However, it is difficult to exclude the risk of retinal detachment after intravitreal injection, especially given that all intravitreal injections were administered by the same physician in our study and the variable incidence rates reported in previous research [6].

Adopting the correct injection technique is critical to minimizing the risk of serious complications. A crucial step in reducing the incidence of RRD may be identifying the correct anatomic location for injection. If the needle were to penetrate posterior to the appropriate site, the anterior base of the vitreous and ora serrata could be damaged, and the entire retina could be breached. Such damage can lead to retinal tears and progress to retinal detachment [22]. Therefore, to minimize the risk of RRD, physicians should avoid the anterior base of the vitreous and ora serrata by targeting the area 3.5 to $4.0 \mathrm{~mm}$ from the corneolimbal margin and, at the same time, should not point the tip of the needle too far posteriorly. Furthermore, to avoid complications such as vitreous incarceration, the sclera should be penetrated obliquely rather than perpendicularly. Indeed, there are reports that a double-plane tunnel technique can significantly lower the risk of RRD. Using this technique, the sclera is first penetrated at an angle of $15^{\circ}$ to $30^{\circ}$, after which point, the needle is repositioned to an angle of $45^{\circ}$ to $60^{\circ}$ while the sclera is still engaged [22-24].

The RRD case in our study occurred in a male patient with myopia (-5.25 diopters) who was treated with three consecutive intravitreal bevacizumab injections prior to occurrence of RRD. A previous study by Meyer et al. [7] reported a higher incidence of RRD in myopic eyes, with four of the five RRD cases having myopia ranging from -1.75 to -5.5 diopters. The authors recommended examining myopic eyes for lattice degeneration, atrophic holes, or vitreous tractions with a contact lens and treating these lesions prior to proceeding with a patient's first injection. Although no definite retinal tear or lattice degeneration was found prior to injection in our case, a careful fundus examination including a contact lens exam may help to prevent post-injection RRD in myopic eyes. Furthermore, the indication for treatment in this particular patient was PDR. The natural course of PDR is a cycle of proliferation and regression of new vessels, proliferation of fibrous tissue, adhesion between the posterior vitreous surface and fibrovascular proliferations, and contraction of the posterior vitreous. Intravitreous injection of bevacizumab could perhaps worsen this natural course by stimulating regression of the vascular component of fibrovascular proliferation with a concurrent increase in fibrosis, eventually aggravating the retinal traction [25]. As this socalled "crunch syndrome" is a well-known contributing factor to tractional retinal detachment, injections should be performed only after careful deliberation in patients with PDR.

Our study population included diseases like acute retinal necrosis and cytomegalovirus retinitis that tend to pair with a high incidence of retinal tear. In these conditions, a hole or tear can form in the necrotic area due to disease progression regardless of intravitreal injection. However, in our study, there was no patient who presented with retinal tear or retinal hole. The small number of patients with these diseases seems to have influenced the results.

Our study has several limitations. First, all the patients enrolled were from the practice of one retinal specialist at a single tertiary hospital. Second, there was only one confirmed case of RRD as a complication, which made it difficult to determine whether or not the risk of RRD depends on injection site, agent injected, or another factor such as the disease being treated. Therefore, further research to answer these questions is needed in the future. However, the strength of our study is that it is a single-center, single-practitioner case 
series with a relatively long follow-up period that included a larger number of patients than in previous studies, which allowed us to minimize the variations introduced by multiple practitioners.

The incidence of RRD after intravitreal injection in our study was similar to that reported in previous studies and to the overall incidence of RRD in the Korean population. This finding suggests that intravitreal injection is a safe treatment modality when performed with a proper technique and safety precautions.

\section{Conflicts of Interest}

The authors have no conflicts to disclose.

\section{References}

1. Gemenetzi M, Patel PJ. A systematic review of the treat and extend treatment regimen with anti-VEGF agents for neovascular age-related macular degeneration. Ophthalmol Ther 2017;6:7992.

2. Arevalo JF, Sanchez JG, Lasave AF, et al. Intravitreal bevacizumab (Avastin) for diabetic retinopathy: the 2010 GLADAOF lecture. J Ophthalmol 2011;2011:584238.

3. Keenan TD, Wotton CJ, Goldacre MJ. Trends over time and geographical variation in rates of intravitreal injections in England. Br J Ophthalmol 2012;96:413-8.

4. Williams GA. IVT injections: health policy implications. Rev Ophthalmol 2014;21:62-4.

5. Grzybowski A, Told R, Sacu S, et al. 2018 update on intravitreal injections: euretina expert consensus recommendations. Ophthalmologica 2018;239:181-93.

6. Karabag RY, Parlak M, Cetin G, et al. Retinal tears and rhegmatogenous retinal detachment after intravitreal injections: its prevalence and case reports. Digit J Ophthalmol 2015;21:8-10.

7. Meyer $\mathrm{CH}$, Michels S, Rodrigues EB, et al. Incidence of rhegmatogenous retinal detachments after intravitreal antivascular endothelial factor injections. Acta Ophthalmol 2011;89:70-5.

8. Clark A, Morlet N, Ng JQ, et al. Risk for retinal detachment after phacoemulsification: a whole-population study of cataract surgery outcomes. Arch Ophthalmol 2012;130:882-8.

9. Jager RD, Aiello LP, Patel SC, Cunningham ET Jr. Risks of intravitreous injection: a comprehensive review. Retina 2004;24:676-98.

10. Olsen $T$, Jeppesen P. The incidence of retinal detachment after cataract surgery. Open Ophthalmol J 2012;6:79-82.

11. Sampat KM, Garg SJ. Complications of intravitreal injections. Curr Opin Ophthalmol 2010;21:178-83.

12. Smiddy WE, Michels RG, Green WR. Lens and peripheral retinal relationships during vitrectomy. Retina 1991;11:199-203.

13. Park YJ, Son GS, Kim YJ, et al. Intravitreal anti-vascular endothelial growth factor injections to treat neovascular age-related macular degeneration: long-term treatment outcomes. J Korean Ophthalmol Soc 2018;59:1142-51.

14. Boyer D, Heier J, Brown DM, et al. Vascular endothelial growth factor trap-eye for macular edema secondary to central retinal vein occlusion: six-month results of the phase 3 COPERNICUS study. Ophthalmology 2012;119:1024-32.

15. Brown DM, Nguyen QD, Marcus DM, et al. Long-term outcomes of ranibizumab therapy for diabetic macular edema: the 36-month results from two phase III trials: RISE and RIDE. Ophthalmology 2013;120:2013-22

16. Campochiaro PA, Brown DM, Awh CC, et al. Sustained benefits from ranibizumab for macular edema following central retinal vein occlusion: twelve-month outcomes of a phase III study. Ophthalmology 2011;118:2041-9.

17. Heier JS, Brown DM, Chong V, et al. Intravitreal aflibercept (VEGF trap-eye) in wet age-related macular degeneration. Ophthalmology 2012;119:2537-48.

18. Holz FG, Roider J, Ogura Y, et al. VEGF Trap-eye for macular oedema secondary to central retinal vein occlusion: 6-month results of the phase III GALILEO study. Br J Ophthalmol 2013;97:278-84.

19. Lang GE, Berta A, Eldem BM, et al. Two-year safety and efficacy of ranibizumab $0.5 \mathrm{mg}$ in diabetic macular edema: interim analysis of the RESTORE extension study. Ophthalmology 2013;120:2004-12.

20. Rosenfeld PJ, Brown DM, Heier JS, et al. Ranibizumab for neovascular age-related macular degeneration. N Engl J Med 2006;355:1419-31.

21. Park SJ, Choi NK, Park KH, Woo SJ. Five year nationwide incidence of rhegmatogenous retinal detachment requiring surgery in Korea. PLoS One 2013;8:e80174.

22. Wimpissinger B, Binder S. Entry-site-related retinal detachment after pars plana vitrectomy. Acta Ophthalmol Scand 2007;85:782-5.

23. Knecht PB, Michels S, Sturm V, et al. Tunnelled versus straight intravitreal injection: intraocular pressure changes, vitreous reflux, and patient discomfort. Retina 2009;29:1175-81.

24. Özkaya A, Alkin Z, Celik U, et al. Comparing the effects of three 
different intravitreal injection techniques on vitreous reflux and intraocular pressure. J Ocul Pharmacol Ther 2013;29:325-9.

25. Arevalo JF, Maia M, Flynn HW Jr, et al. Tractional retinal detach- ment following intravitreal bevacizumab (Avastin) in patients with severe proliferative diabetic retinopathy. $\mathrm{Br} J$ Ophthalmol 2008;92:213-6. 